University of Nebraska - Lincoln

DigitalCommons@University of Nebraska - Lincoln

Faculty Publications: Department of Teaching, Department of Teaching, Learning and Teacher Learning and Teacher Education

Education

2020

Selfies as Postfeminist Pedagogy: The Production of Traditional

Femininity in the US South

Mardi Schmeichel

Stacey Kerr

Chris Linder

Follow this and additional works at: https://digitalcommons.unl.edu/teachlearnfacpub

Part of the Curriculum and Instruction Commons, Gender and Sexuality Commons, Regional Sociology Commons, and the Teacher Education and Professional Development Commons

This Article is brought to you for free and open access by the Department of Teaching, Learning and Teacher Education at DigitalCommons@University of Nebraska - Lincoln. It has been accepted for inclusion in Faculty Publications: Department of Teaching, Learning and Teacher Education by an authorized administrator of DigitalCommons@University of Nebraska - Lincoln. 


\title{
Selfies as Postfeminist Pedagogy: The Production of Traditional Femininity in the US South
}

\author{
Mardi Schmeichel, ${ }^{1}$ Stacey Kerr, ${ }^{2}$ and Chris Linder ${ }^{1}$ \\ 1. College of Education, University of Georgia, Athens, Georgia, USA \\ 2. College of Science and Engineering, Central Michigan University, Mt. Pleasant, Michigan, USA \\ Corresponding author - Mardi Schmeichel, College of Education, University of Georgia, 110 Carlton Street, Athens, \\ GA 30607, USA; email mardi@uga.edu
}

\begin{abstract}
This article describes a study of selfies posted on Instagram by a group of predominantly white, college women at a large public university in the US South. Selfies are used as data to explore how performances of traditional femininity are legitimated, authorized, and reinscribed through photoposting practices. The authors argue that these performances circulate a public pedagogy of femininity and contribute to notions of traditional gender roles and physical attractiveness that reinforce classed and raced norms of beauty. The selfies, which idealize the southern lady [McPherson, Tara. 2003. Reconstructing Dixie: Race, Gender, and Nostalgia in the Imagined South. Durham: Duke University Press], characterize a particularly regionalized type of self-promotion in the visual economy facilitated by Instagram. Drawing on theorizations of postfeminism, the authors describe how the hyperfemininity performed in these selfies can be interpreted within the morass of neoliberal discourses that on one hand encourage women's adoption of traditional gender practices while at the same time discourage the critique of systems that marginalize women.
\end{abstract}

Keywords: femininities, identities, popular culture, women, higher education, North America 


\section{The selfie debate}

Within feminist social media circles in particular, there have been lively debates about whether selfies are creative expressions of women's power or pleas for validation (c.f., Eler 2013; Ryan 2013). Everyday Feminism, a feminist online magazine, facilitated an intense discussion on the topic on its website in late 2013. The comments ranged from defending women's rights to celebrate and value their bodies to questioning anyone's need to seek confirmation of worth outside oneself. Many of the posters - who were predominately women-stated adamantly that they posted pictures "for themselves." These types of comments described the confidence and esteem boost that posters gained through selfies. Discussion participants framed selfies as a vehicle to display evidence of instances in which posters felt particularly positive about themselves. In contrast to the pro-selfie perspectives, a much smaller group of critics pointed to the persistence of a patriarchal system in which women are valued on the basis of their appearance: these posters argued that selfies reinscribe a cultural obsession with appearance. Some of these same posts also pointed to the disproportionate over-representation of women and girls among selfie posters and contended that this discrepancy signaled the inherent gender inequity underlying the practice. Mixed between these two positions was a strong chorus of "who cares?" Participants taking up this position declared that if "I like to do it, and it makes me happy, makes me feel good, why should I stop and why would it be questioned?"

Indeed, why are things that make women more confident about themselves and make them feel good-and selfies in general-worth questioning? We respond to these questions in this article through a description of a specific set of selfies in our study of images posted to Instagram at a large public university in the US South. We used the nearly 300 selfies in this data set-posted by a group comprised predominantly by young, white women - to explore how performances of traditional femininity are legitimated, authorized, and reinscribed through selfie practices. Building on our analysis of the selfies, we argue that these performances circulate a public pedagogy of femininity that contribute to notions of traditional gender roles and physical attractiveness that reinforce classed and raced norms of beauty. The selfies we describe in this article, which we have labeled the southern lady (McPherson 2003), characterize a particular, regionalized type of self-promotion in the visual economy facilitated by Instagram and other social media networks. Drawing on theorizations of postfeminism, we describe how the hyperfemininity performed in these selfies can be interpreted within the morass of neoliberal discourses that on one hand encourage women's adoption of traditional gender identities and practices (particularly those related to production and consumption) while at the same time discourage the critique of systems that marginalize women.

\section{Context of the study}

The selfie research described in this article comes out of a larger study in which we are exploring women's dress at University of Georgia (UGA) football games in Athens, Georgia, a community of around 120,000, located in the southern United States. As part of the data gathering for that project, we searched for and collected publically available photos posted 
to Instagram with the hashtag \#godawgs, a commonly used phrase and hashtag associated with UGA and the football team. We collected all photos posted during the 24 hours surrounding the day of first home game of the season in 2013. This search yielded 5,017 photos. Of those photos, we identified 1,592 photos that were portraits, which we defined as including at least part of the body of at least one person who appeared to be posing for the camera. In the multiple rounds of analysis that followed, the research team reviewed every photograph to determine the characteristics germane to the study on women's dress.

Our analysis of the type of portraits revealed that almost $20 \%(n=293)$ were selfies, or self-portraits of a single subject. Considering the social aspect of the football event-over 100,000 people are reported to inhabit the square mile around the football stadium before and during the game-we were surprised that selfies constituted such a significant proportion of the photos. When we identified $80 \%(n=233)$ of the subjects in these selfie images as women, and considered the juxtaposition between the overrepresentation of women in a subset of photos and this traditionally hypermasculinized event, we decided we needed think further about what was happening as these single-subject portraits of women were circulating within Instagram, a popular social networking site (SNS) among young adults.

\section{Instagram}

According the 2015 Pew Research Center report on social media use (Duggan 2015), 55\% of Internet users between 18 and 29 have an Instagram account, making it second only to Facebook in SNS use among people in the age group. Instagram's reliance on images and "likes" as the primary means to interact and communicate works to feed the visual marketplace at a much higher rate than other SNSs. By this we mean that while Facebook and Twitter incorporate images, users also rely heavily on texts, shared posts, and other types of non-imaged based interactions. Images dominate Instagram. There is text on Instagram, but most messages are short. The almost exclusive focus on images on Instagram, specifically within the context of its increasing popularity among young people, points to an urgent need to understand how images of bodies are produced and read in digital spaces and the "scopic economy of bodily capital assessment" (Skeggs 2001, 202) which has created a hierarchy in which we are all organized on the basis of "bodily and visual value" (202). While the practice of corporeal assessment and ranking are not new, Ringrose et al. contended that technologies are providing "new ways for value to circulate through images, and for value to become materially marked on particular bodies as part of that process" $(2013,317)$.

There are many new digital technologies contributing to changing the ways we are reading, evaluating, and measuring our bodies, but the scopic economy of Instagram is particularly well suited to promoting particular corporeal performances. Through the circulation of images, Instagram reproduces and expands systems in which some bodily productions have more currency than others. This way of framing Instagram aligns with Hayward's description of a system of neoliberal optics which is "fundamentally transactional in nature, having impacted on both what it means to see and be seen as an individual" $(2013,207)$. Our close examination of images associated with this college football hashtag demonstrated how this SNS has contributed to the authorization of selfie practices that not only mirror what young women produce in real life (or "IRL") but magnify and 
pin down the fleeting and temporal events that occur during Saturdays in Athens. Via Instagram and other SNS, the selfies young women post of themselves circulate well beyond Athens, Georgia, and beyond the day in which these events occurred. As such, the normalizing potential of the kinds of femininity performed at this event and produced in these photos has expanded exponentially. This understanding builds on Hayward's acknowledgment that the power of neoliberal optics is derived "not only from their efficacy as tools for governance, control and exploitation but also from the ways in which they have been made to seem natural and intimate to our everyday lives" (207). In the following section, we will describe some of the qualitative methods we tinkered with in order to produce and represent the data produced through this new digital platform.

\section{Experimenting with social media research methodologies}

The use of publically available social media data in research is relatively new and there are significant methodological challenges in research that seeks to explore and represent how people represent themselves visually. In the following sections, we provide extended descriptions of the two specific data analysis processes used in our study: the process through which we assigned gender and race to the subjects in the photos, and the problems and tensions embedded in that process and our use of a model to reenact photos from the data.

\section{Photo analysis}

Assigning subjects' gender and race through image analysis is a highly problematic practice, requiring researchers to lean on assumptions about embodied gender and racial characteristics in order to "assign" these identifiers. On the other hand, ignoring gender and race all together would be equally problematic. Our decision was for each researcher to assign gender and race to the subject in each selfie, conferring with one another if there was any ambiguity, which occurred frequently (and led to some interesting conversations). Despite the diligence and concern for power and privilege with which these particular tasks was completed, we do not wish to convey the results of this part of the analysis in terms of the "accuracy" with which we determined the gender and race/ethnic group with which the subject identifies: the results we describe are only accurate in the sense that we made every effort to apply uniformly our interpretations of commonly held assumptions of the physical characteristics that signify lived gender and race identification. We believe that the lived raced and gendered experiences of the subjects of these images are far more complex and varied than what could possibly be captured by the limited set of categories through which we have analyzed this data. We also believe that research that uses bounded gender and race categories to describe data still has an important role to play in social research, particularly in continuing to point to structural and systemic inequities that have material consequences on the basis of gender and race.

\section{Model methods}

There are significant limitations in any attempt to represent visual data with only words. As such, we decided that it was critical that we present some type of visual account of the images discussed in our analysis. However, there are considerable ethical concerns about the rights of the subjects of internet-based research (Markham and Buchanan 2012). These 
concerns are compounded for studies like ours, which draw from publicly available data instead of the data produced by willing, knowing participants. While review boards may not insist that researchers drawing from publicly available data gain subjects' consent to the use their posts as data, digital researchers must consider the consequences and potential harm facing subjects if their image, likeness, user name, etc. are revealed. Further, photos posted to Instagram are copyright protected and cannot be reproduced here to illustrate our analysis.

To address the issues described above, we tried several different ways of altering photos in ways that would preserve the essence of the photo while obscuring the identity of the subject. For example, we tried photoediting techniques that blurred subjects' faces or placed an opaque box over subjects' eyes. Additionally, we tried an application that converts images to drawings. None of these methods produced an image that protected the user's identity and captured the characteristics of the photo we were trying to represent. We eventually came to the conclusion that the best approach would be to reproduce the photos. Therefore, we hired a model to reenact photos from the data. We showed the original photos to the model, who attempted to replicate the clothing, lighting conditions, and backgrounds present in the original photos, and then shared those photos with us. One of the authors then used phone-based photoediting applications to render the photos as similar to the original data as possible. We were able to achieve a close simulation of the original photos in terms of the elements we describe in the analysis. The photos included in this article, then, are examples of the photos in the data but are not from our data.

\section{Analyzing selfie images}

Of the 293 selfies in the data, we identified 233 of the subjects in the photos as women. Among the 233 selfies with women subjects, we labeled about $25 \%(n=58)$ as southern lady selfies. Seven of women in those images were identified as African American, two as Asian American, and one as Hispanic. There were many repeated and related codes among these images which created a traceable pattern within our earliest efforts to make sense of the data. Taken together, these codes align with McPherson's work on women and race in the US South and her rich description of the southern lady as defined by appearance and performance and as a "hyperfeminized figure" $(2003,19)$ around which the South constructed its postbellum identity (39).

In her analysis of southern femininity, McPherson relies heavily on Gone with the Wind as a source to understand how notions of womanhood were tied up with race, class, and place in the US South at the beginning of the twentieth century. She points to the novel's first sentence, which states "Scarlett O'Hara was not beautiful," to assert that white southern femininity, while not defined by beauty, has "something to do with appearance and performance" (53). As the former confederate states worked to reclaim their status and credibility after the US Civil War, the southern lady was an indefatigable symbol of what was good and right about the South. The idealized symbol of the southern lady, an unquestionably positive fixture of southern culture, has had significant and enduring consequences on notions of femininity in the South. Femininity may be associated with appearance and performances in many places, but the depth of this relationship is particularly important 
to acknowledge in the American South where, McPherson argues, the southern lady became a "limit figure against which southern women evaluate themselves - whether or not individual women chose to pursue it, it has material effects on every individual womanit has a realm of influence that encompasses even those who reject it" (152). McPherson asserts that the southern lady ideal, an image of womanhood that emphasizes a "highly mannered performance of gender" (152), is more enduring and specific than images of womanhood than any other region of the United States. While the political and economic status of the US South has changed considerably since the Civil War, McPherson notes that the cult of the southern lady continues to influence life in the south today and is still shaped along class and race lines. The difference between women in the South and women elsewhere, "has been fetishized, fixated on, and marketed for so long that it has taken hold, creeping into white southern consciousness like kudzu" (152). The performance of the femininity we examined in these selfies reflects the history of race, gender, and place specific to the South.

Our analysis of the images is based on the understanding that the details we used to analyze the photos were available to us largely because the posters intended them to be. In other words, we assumed that the subjects' were purposeful in their choices. As Pham notes, the subjects of selfies play a significant role in producing and controlling the way they are represented:

They make choices about when to take a selfie ... where to position the head, face, and body in relation to the camera; which ... hashtags to use; how to caption, crop, and otherwise edit the image; and when to share it online or whether to share it at all. $(2015,224)$

Additionally, our analysis builds on the assumption that viewers of the photos are likely to draw upon the same sorts of details as we did to read gender performances in these photos. This approach follows scholars like Dobson (2014), Pham (2015), and Ringrose (Ringrose and Harvey 2015; Ringrose et al. 2013) who analyze digital content and signifiers of femininity. The descriptions of the ways participants in these studies "read" gender performances in social media photos parallels our own attempts to use different components of the images to interpret the kinds of femininity produced in them.

In the following section, we provide detailed descriptions of the ways the southern lady appeared in the data. This detail is provided (1) in response to the absence of similar descriptions in other qualitative research that categorizes users' photo representations on social media and (2) to provide a specific link between posters' sartorial and embodied practices and the particular brand of hyperfeminity produced in the photos.

\section{The southern lady}

While many of the women in the other selfies within our dataset are dressed in casual clothing, the southern lady subjects are characterized by their formal wear. These subjects are wearing dresses and dressy blouses in soft and flowy, expensive-appearing red, black, and white (the school's colors) fabric that often seems to be a chiffon, silk, or high-quality 
soft cotton. Also visible in these images is a significant amount of jewelry, like chunky, statement necklaces and distinctive earrings. While much of the clothing by subjects in the other images reflects the feminized version of men's sportswear or gender neutral clothing (e.g., t-shirts emblazoned with the university logo), the clothing visible in the Southern Ladies images demonstrates a version of traditional feminine dress for formal occasions including strapless dresses, clothing with bows, lace, and rounded necklines. Further, the fit of the clothing is distinctive, emphasizing feminine curves without revealing what might be considered "too much" skin. For example, shirts or blouses are form-fitting and draw attention to bust lines but do so without revealing what might be considered by some to be an inappropriate amount of cleavage. Similarly, dresses worn by the Southern Lady are often near-knee length as opposed to "mini" (see Fig. 1).

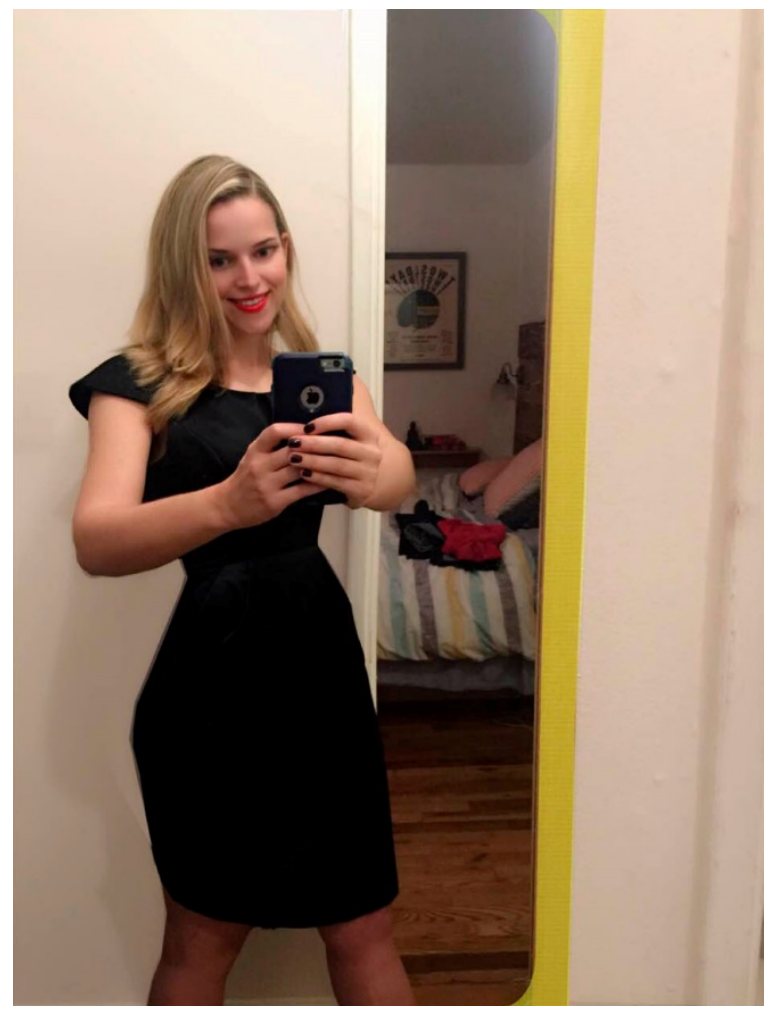

Figure 1. Model recreates a Southern Lady mirror selfie.

Lastly, many of the subjects in these photos are wearing bright, glossy red lipstick, a make-up choice that emphasizes their (straight) white teeth, further enhanced through the use of photoediting techniques in which the contrast and color saturation of the image has been manipulated (see Fig. 2). The effect of this editing in many of the photos creates a stark contrast between the pore-free skin of the subject and red lips. 


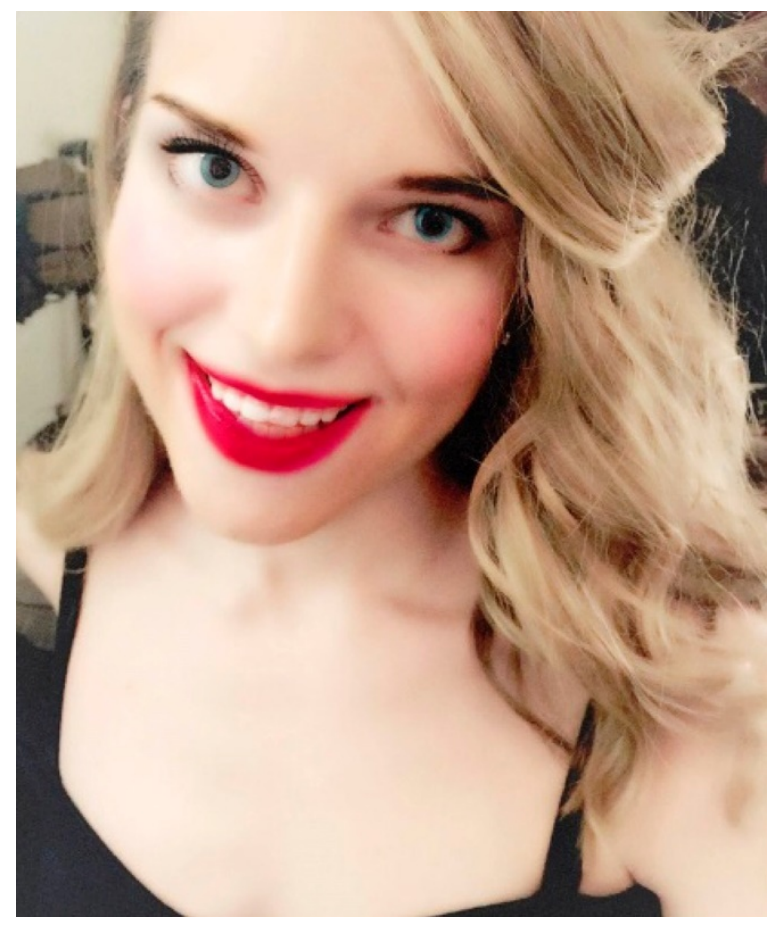

Figure 2. A recreation of a heavily edited southern lady selfie.

Most of the photos appear to have undergone significant editing. For example, many images show an intense contrast between the southern lady's face and/or body and the remaining elements of the photograph. This is achieved through the use of filters or manual edits that adjust the photograph's brightness, highlights, shadows, exposure, contrast, and sharpness. The sharp contrast between the subject and the background of the photograph works to create a greater emphasis on the subjects' features, and in particular, their faces. It is important to note that while these photos have a significant emphasis on subjects' faces, there is an almost total absence of any (normal) characteristics that might be considered "flaws," such as pores, dark circles under eyes, and yellowed teeth. This suggests the use of photo editing applications geared toward the alteration and "perfecting" of a subject's appearance in selfies (e.g., Makeup Plus, Photowonder).

Further, the Southern Ladies appear to use romantic and lightening Instagram filters (e.g., Rise, Earlybird, Sierra, Lo-Fi, and Walden) to soften, and arguably feminize, their photographs (see Fig. 3). Despite the boldness of the red and black colors of their clothing, the photographs do not have a bold appearance. Instead, they appear light, airy, and clearly curated. 


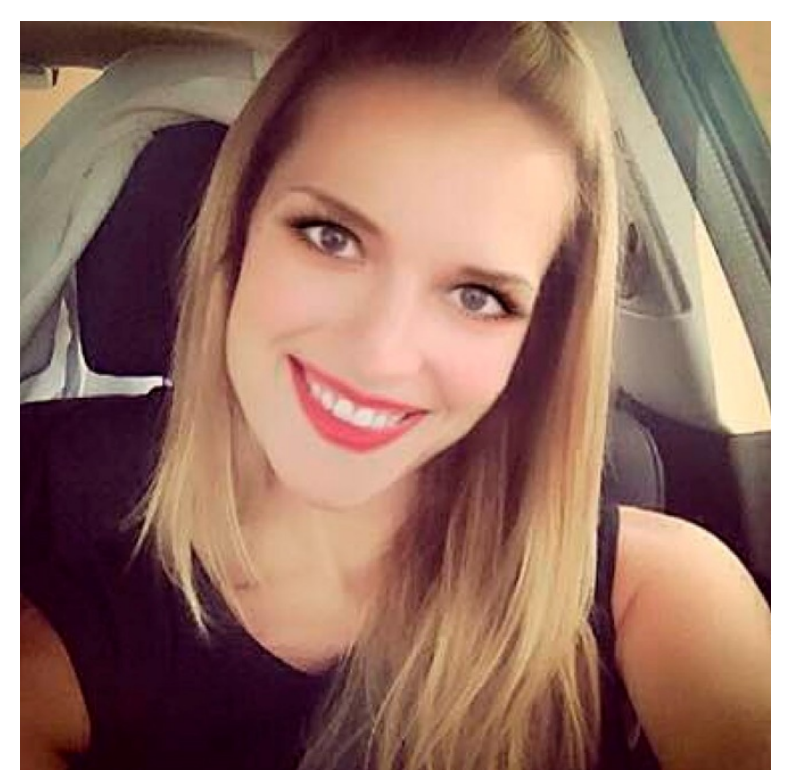

Figure 3. A recreation of a southern lady car selfie with softening filters.

While the vast majority of all selfie subjects were smiling in the photos, the southern lady subjects did not reflect the same degree of glee or enthusiasm evident in selfies in general. Instead, these photos are more restrained, reserved, and measured. For example, the subjects in these photos seem to be carefully posed. The images lack elements of motion, action, and spontaneity (e.g., blurred images, silly expressions) evident in the other selfies. Further, subjects appear in the photos at angles and in positions in which particular aspects of their appearance are emphasized. The vast majority of these selfies have been taken from above, meaning the subject was holding the camera above eye level when snapping the photo. This angle elongates every portion of the body that appears in frame and in particular, makes the face appear thinner. In multiple photos, the angle of the subject and camera has a focus on subjects' hair. In these photos, hair was carefully placed, typically cascading on one side to build up the look of thickness (while at the same time exposing the often bare other shoulder). The effect was enhanced through the crop of the photo, which further drew the viewer's eye to focus on the subject's hair or jewelry.

\section{The production of traditional femininity through southern lady selfies}

The clothing, makeup, posing, and editing used in the southern lady images work together to achieve a hyperfeminine gender performance that differs significantly from the images of women in the other selfies. In the southern lady images, attention to a traditionally gendered performance has been emphasized through the choice of technologies that reinscribe the male/female binary. The feminized clothing is particularly important to note in the context of the sporting event from which this data was drawn. The sartorial choices evident throughout these images, like dresses and other formal clothing designed specifically for 
women signal a particularly strong display of gender difference within the setting of a football game.

The focus on appearance and beauty also works to reinscribe the femininity on display in these photos. The posters seem to have made a significant effort to align themselves closely with traditional white, upper-middle class standards of feminine beauty, as demonstrated through the subjects' make-up and hair, posing, and photoediting. In other words, by taking advantage of a variety of "old school" technologies - clothing, makeup, posing-as well as new technologies such as the digital manipulation of photographythe southern lady images that circulate in these selfies reinscribe a traditional femininity organized around/on a binary (Ringrose 2013). Specifically, we contend that this analysis indicates that the southern lady selfies produce "a recognisable form of idealized feminine corporeality" (Ringrose 2013, 122). The soft, clearly gender-normed clothing works together with meticulously cultivated hair, makeup, and body presentation to emphasize a visual image of womanhood rooted in traditional notions of femininity.

\section{Race and class}

What this analysis also reveals is that the traditional feminine ideal is itself incredibly narrow. The southern lady image is largely limited to bodies that are white, thin, abled, and conventionally attractive as determined by current beauty standards particularly associated with whiteness. At least part of the explanation must be attributed to the underrepresentation of students of color among the student population at the UGA: in Fall 2013, 73\% of the 26,278 undergraduates self-reported as white (Moore 2013, 21). However, the absence of women of color from these images also indicates that women of color do not desire to produce southern lady selfies, either in real life or in selfies posted to Instagram. That only 10 of these images of women of color were tagged as southern lady images indicates that there is differential access on the basis of race to the production of this subject or the desire to produce this subject.

Our finding about the limitations on who could perform the ideal southern lady align with the results of Hamilton's study of college-aged women and her conclusion that "gendered-embodied capital is not equally available to all individuals" (2007, 147). Hamilton argued that the understanding required to produce the cultural ideal of embodied whiteness required classed knowledge and resources: "this appearance requires knowledge about styles and trends and the money necessary to buy and embody them. Not everyone is, therefore, capable of producing the kind of femininity that can bring benefits" (168-169). The material requirements to perform this particular version of the traditional feminine ideal are also clearly on display in the southern lady images. The clothing, hair, makeup, and self-presentation in the photographs work together in the images to curate a "repertoire of self" (Skeggs 2005, 973) that reveals a specifically middle/upper middle-class location. This is achieved visually through what appears to be the careful selection of expensive (looking) trendy clothing, updated and well-maintained hairstyles, and expertly applied makeup. Further elements of the subjects' appearance contributing to the class location were less material but important nonetheless. The gleaming white teeth, flawless (and poreless) skin, and carefully coiffed hair give the overall impression of 
that each of these bodily properties has a great deal of value (Ringrose 2013). The cumulative effect of each of the photos, enhanced by expert editing, creates the impression that the subject went to significant expense and effort to achieve the southern lady look. In this context, the production of traditional femininity appears to come at a cost (that not all can pay). Whether or not the subjects' appearance accurately reflects their actual socioeconomic status, the effect of the image has consequences for the production of a type of femininity that is bound tightly with a particularly elite class position.

\section{Selfies as public pedagogy}

These selfies have a tremendous normalizing potential. While for individual women, embodying the southern lady and circulating the image may work to associate her with the idea of that idealized model, the image is also nested within a specific context in which gender roles and feminine norms are constrained. This argument is highlighted by the limited variation in the southern lady performance visible in these images: above all, these images can be characterized by their remarkable similarity to each other. This finding resonates with results of a study conducted by Mendelsen and Papacharissi of the photos college students posted to Facebook. They found that "The commonality of the images ... demonstrates that, while the outfits and locations change ... the nature of the poses do not ... These images are highly conventional, both in terms of their subject matter and their aesthetics" $(2011,267)$. The unanimity of the images posted to Instagram by college-going women of this age and race group - within this study and at any given time-is astounding. However, it is not a topic that has received a great deal of attention within a research landscape dominated by the more provocative topics like the sexting "crisis" and the hypersexual images posted by young women. Considering the consequences of young people's constant production and consumption of such eerily similar photos is overdue.

Like all media sources, social media sites serve as public pedagogy. Young women are substantial producers and consumers in social media markets. They have an increasing influence over the "cultural field" that Giroux described in his important piece on public pedagogy and neoliberalism. The cultural field, as Giroux describes it "plays a central role in producing narratives, metaphors, and images and in desiring maps that exercise a powerful pedagogical force over how people think about themselves and their relationship to others" $(2004,499)$. Instagram, in particular, as a primarily visual medium, is a powerful tool to shape the cultural field through its contribution to determining what performances of normal can and should look like. In this way, the production of selfie photos in which so many young women look the same contributes to notions of how we think young women should produce themselves.

Of particular concern in relation to the data described in these images are the notions of femininity and gender that are normalized through photo circulation. While there were other kinds of images within the selfies, producing other visual performances of femininity and gender, the southern lady selfies represent a significant proportion of the whole. In this sense, the images can be seen as purveying a particular kind of public pedagogy of femininity that tends to the intelligibility of the gender binary through the promotion of traditional femininity. These selfies can be framed as spaces in which public lessons about 
southern (white, upper-middle class) femininity are being taught. The images are shaping notions of who southern women should aspire to be.

In her discussion of gender in the US South, McPherson asserted that lesson on southern femininity "are learned daily and overtly" (2003, 147). While southern women have been teaching these lessons in person, daily and overtly, to new generations for decades, the advent of Instagram and other social media outlets make it possible for these pedagogies to be public on a much wider scale. Through their circulation, these selfies are at work on the norms of traditional femininity and the ideal Southern woman in times and spaces that far exceed lessons in the home or the game day experience in this particular community.

To recognize these selfies as a type of public pedagogy of femininity is not to assert that women viewers of social media are mindlessly absorbing and mimicking the messages in the images they consume. Rather, as social media scholar Amy Dobson contended, we can position women as thinking, acting agents while still acknowledging the impact of visual media images on women's perceptions of themselves. She argued:

the kind of overwhelming commodification of female bodies we see in visual culture would suggest an amount of cultural pressure on girls and young women to conform with narrow standards of bodily representation, even if we acknowledge and take into consideration the fact that individual girls and women negotiate such pressures differently ... there are few feminists who would disagree that appearance-based pressures exist for girls and women in relation to dominant cultural norms and to some extent shape the subjectivities of the girls and women who must negotiate their way around, though, out of, or into the terrain of feminine subjectivity. $(2014,101)$

Drawing on this understanding allows us to acknowledge that while all young women participating in social media have particular, individual, local experiences of it, their experiences are embedded within rigid systems of power that are shaping their actions, choices, and ways of interacting in those spaces, whether they are aware of these systems or not.

\section{Theorizing the postfeminist subject position}

In addition to acknowledging that different women will respond to the consequences of these images differently, it is also critical to avoid the bandwagon of condemning these practices as narcissistic. Instead, a more fruitful focus is questioning why the performance is desirable. To think about this question, we looked to the postfeminist theorizations on traditional femininity. Theorizing postfeminism has served as a promising resource to understand why traditional femininity appears to be an attractive option to many young women at this neoliberally informed social/political/economic moment.

The understanding of the production and performance of traditional femininity in these selfies relies first on West and Zimmerman's definition of gender as "the product of social doings of some sort" $(1987,129)$. Rather than being a static form of "being," gender is understood to be continually performed and read through interactions with others (Butler 1993). This perspective makes it possible to think of gender as a subjectivity created through 
a constant state of production rather than a state a being or an identity with which one is born. Further, this stance recognizes that different types of gender performances can be enacted. While there may be a variety of ways that cisgender women can produce and perform femininity, as Skeggs notes, access is not equal: "Being, becoming, practicing, and doing femininity are very different things for women of different classes, 'races,' ages and nations" (2001, 297).

The southern lady performance of femininity produced for and disseminated through these selfies highlights the parameters placed on what kind of woman can perform her online. We identified a handful of the subjects in the images as women of color, but the overwhelming majority of the subjects in the photos were identified as white. Further, the material and embodied characteristics displayed in the photos (e.g., clothing, jewelry, hairstyles, body type, etc.) signal attributes that are often associated with white, upper middleclass norms of beauty and attractiveness. These markers indicate that at least in terms of Instagram posting practices, there is some rigidity governing who can post southern lady selfies and norms for the hyperfeminine, classed, and raced performance curated in images. The subjects in this data demonstrate a notable lack of difference, indicating that there is little flexibility or fluidity in terms of who can occupy the southern lady subject position and how it can be enacted.

In addition to recognizing the factors complicating who can achieve the traditional feminine performance in these selfies is the need to question why the performance is desirable. To think about this question, we turned to feminist research on traditional femininity. The celebration of traditional femininity is a vexing concern for some feminists, who have interpreted it as a rolling back of hard-won progress to eliminate women's association with these rigidly gendered and often marginalized subject positions.

Theories analyzing post-feminism offer a way of making sense of the return of traditional femininity. Most definitions of postfeminism include the understanding that the postfeminist condition shapes a climate in which gender equality is perceived to have been achieved. One consequence of this perspective is that it has made space for a "resurgence of ideas of natural sexual difference" (Gill and Donaghue 2013, 246) or what Garcia-Favaro described as a cultural sensibility that is "deeply invested in reductive, dichotomous understandings of gender" $(2015,373)$. This "men are men / women are women" perspective has been of particular interest to media scholars, who have sought to understand it against the backdrop of the proliferation of the digital platforms which have allowed women to engage in the self-production of a variety of traditionally feminine performances in the areas of fashion, beauty, parenting, and crafting on an entirely new scale (Duffy and Hund 2015).

Diane Negra points out that it is not "simply coincidence" $(2009,41)$ that traditional femininity has been reembraced at the same time that the goals of feminism are perceived to have been achieved. The "idealization of traditionalist femininities" (152) invites women "to devote themselves to home and family in a display of 'restored priorities'" (118). In other words, because women now don't need to worry about the patriarchy and other inequities, there is time and space for a return to these traditional feminine pursuits. As such, these interests can offer the pleasure of an "idealized, essentialized femininity that 
symbolically evades or transcends institutional and social problem spots" (Tasker and Negra 2007, 10).

Angela McRobbie argues that young women have adopted traditionally feminine gender performances as a result of their changing economic status and contends this can be seen as a "nervous gesture" by young women "who have become aware that their coming forward and competing on the labour market with men as their equal has certain repercussions [such as] impact[ing] their negotiation of heterosexuality and potentially detract[ing] from their desirability" $(2009,66)$. Because, as Susan Brownmiller observed, "femininity serves to reassure men that women need them and care about them enormously," $(1984,17)$ the performance of femininity can be read as effort to resecure gender binaries and the gender order in changing economic times. As a result of this turn, which McRobbie labeled the postfeminist masquerade, "it becomes increasingly difficult to function as a female subject without subjecting oneself to those technologies of self that are constitutive of the spectacularly feminine" (60).

For Rosalind Gill, postfeminism is a complex, multilayered discourse that manages to combine antifeminist and feminist notions, resulting in contradictory expressions of both feminism and gender ideals. This intermingling is highlighted, for example, in increased feminist activism in digital spaces alongside the subjection of women's bodies to a kind of surveillance "with no historical precedent" $(2008,442)$. Critical to our analysis is the emerging body of work that theorizes of postfeminism in terms of its relationship with neoliberalism. This intersection is highlighted, for example, in Gill's description of what she described as the "powerful resonances" operating between postfeminism and neoliberalism: $(2008,443)$ :

Both are structured by a current of individualism that has almost entirely replaced notions of the social ... or any idea of the individual as subject to pressures, constraints, or influence from outside themselves. Secondly, it is clear that the autonomous, calculating, self-regulating subject of neoliberalism bears a strong resemblance to the active freely choosing, self-reinventing subject of postfeminism, [suggesting that postfeminism is a] sensibility that is at least partly constituted through the pervasiveness of neoliberal ideas.

The connection Gill and other feminist media scholars draw between postfeminism and neoliberalism is a critical lens, we argue, for interpreting what is produced in and through social media. In particular, it provides much needed context to think about the selfie debate described in the introduction-about what individuals may be working toward and gain through selfies. When neoliberalism is foregrounded, it is possible to understand how the promotion of self-affirmation and self-care dovetails with the neoliberal promotion of technologies of the self over concerns for structures and processes that systematically marginalize groups.

Gill has addressed this concept recently in her response to critiques of the relevancy of postfeminism (Gill 2016a, 2016b). In these accounts, Gill refutes the notion that the current "luminosity" of feminism in the media indicates that we have moved beyond postfeminism. Instead, she makes a case for the ways in which this new form of feminism is 
inextricably linked with neoliberal technologies that actually undermine core feminist principals. One tenet of her argument closely linked to this study rests on the circulation of neoliberal feminism in the media. Neoliberal feminism, which is embedded in confidence cult(ure), (Gill and Orgad 2015), is characterized by the profuse presence of articles, tips, apps, etc. endorsing a psychologizing discourse of self-esteem and self-love and the promotion of strategies to boost women's confidence and belief in themselves. This internalized and individualized focus on the self detracts from the consideration of structures, institutions, and processes that create and perpetuate the need for self-care or the consideration of how one's actions maintain status quo power relations and inequities. Gill argues that through this version of neoliberal feminism, "the solution to injustice is to work on the self rather than to work with others for social and political transformation" (2016a, 617).

Cultivating one's personal appearance and working to produce a hyperfeminine performance to post to Instagram can be interpreted within the frame of neoliberal feminism. "Feeling good" about oneself as an Instagram poster is contingent upon the labor of producing and posting pictures that will receive affirmation of others through "likes" and comments, not in critiquing embedded social structures that create a need and motivation for posters to seek some kind of public response to their image. Forces that have caused posters to pursue external confirmation of their value are not questioned. That the vast majority of image posters are women is rarely critiqued. In other words, discussions about selfies rarely address why appearance is a commodity that can yield validation, esteem, confidence, or why the burden is on women-not men - to find a way to feel good about themselves through posting selfies to social media. As Gill and Orgad contend, the need to be confident is a new technology of self that is "profoundly gendered" $(2015,339)$. Gill's accounts of neoliberal feminism and confidence cult(ure) offer frames to interpret these selfies, and any potential defense of them as a site of women's self-work and self-care, as a "turning away from structural inequalities and collectivist critiques of male domination ... by repudiating the injuries inflicted by the structures of inequality" (330).

Theorists examining postfeminism as "an object for analysis" (Gill and Donaghue 2013, 246) contend that in these postfeminist times, many women enjoy the perception that they have a great deal of autonomy and choice. They argue that in particular, many middle and upper middle class, white, heterosexual women hold the perception that feminism has achieved it goals and that women have the freedom to plot path they choose. The perspective that this freedom exists, for some groups of women, makes it possible to frame the practice of posting pictures of oneself wearing a dress at a football game on social media as a behavior in which women freely choose to engage. "Postfeminist discourse asserts and celebrates the existence of choices and the rights of women to act in ways that give them pleasure ... [including] the pleasure of being pretty" (Gill and Donaghue 2013, 248). But this sensibility also operates outside of a critique of the beauty/fashion complex or a consideration of what constitutes "pretty" within worldviews shaped by gender relations which are still informed by patriarchy. In this way, these notions of choice, agency, and freedom "occupy a landscape that is unmarked by (gendered) power or inequality" (Gill and Donaghue 2013, 248).

In addition to being interpreted through the frame of postfeminism, the analysis of traditional femininity produced in the selfies demands to be placed specifically in the context, 
place, and history of the American South, which contributes significantly to the particular manifestation of the classed and raced femininity produced in the selfies. The particular configuration of gender roles in this region is informed by the historical valorization of a hyperfeminized performance of white womanhood shaped by entrenched class differences and atrocious racial inequity. As McPherson (2003) described, the southern lady performance was intended to signal the race and class differences of one group of southern women from others. Constructions of femininity are always local, partial, and contingent, but as McPherson explains "the regional fixation on, and deployment of, a particular feminine ideal reaches a different level in the [American] South" (152). These selfies must also be interpreted, then, within the complex, historical race and class relationships that shape notions of acceptable and desirable performances of femininity. Southern lady selfies may be new technology, but they have deep and violent roots.

\section{Researching traditional femininity in postfeminist times}

We want to begin this conclusion by describing what this study does not do. We do not attempt to answer the question about whether or not selfies are good or bad for women. In fact, we would question the usefulness of these kinds of discussions. Instead of panicking about selfie practices or encouraging young women to stop, energies would be better focused on understanding the power structures that create the neoliberal impetus for selfpromotion and hyper-feminine performance within a highly gendered visual economy in which images are "traded like currency" (Ringrose et al. 2013, 319). Therefore, it is important that discourses of selfies not produce young women as the "problem," but rather draw attention to the structures that are governing these practices and making them feel necessary.

In this analysis, we are also not seeking to describe how individual women experienced or perceived posting selfies, nor are we trying to show the "lines of flight" within these practices (see Gill 2008; Gill and Donaghue 2013 for valuable critiques on the shift toward a focus on individual agency). We are certain that individual women experienced performing the southern lady and posting and viewing the selfies in a wide variety of ways, some undoubtedly positive, liberating, and potentially even radical. The absence of attention to these aspects of the phenomenon is not intended to deny that they existed but rather to focus attention beyond individual experiences, and to consider the "cultural habitat of images [that] may be internalized to form a pernicious disciplinary regime" (Gill 2008, 438). This turn away from the radical potential of individual selfie posts to a consideration of the structural consequences for all of us is intentional. As Gill and Donaghue (2013) note, the attention paid to individual experiences and agency in popular culture and contemporary feminist theorizing emphasizes and celebrates women's autonomous choices "by a corresponding downplaying or even complete evacuation of any notion of influence" (240). In other words, "the personal is definitely not political" (248).

Importantly, the link between our study and the consideration of selfies in general has significant limitations: our dataset was drawn from a very specific, regional context and is informed by the sports culture, university culture, and socioeconomic, historical, and racial contexts that shape this particular community. Our reliance on data linked to a hashtag 
associated with an American college football team further narrows the applicability of our commentary to other contexts. The performances of femininity we examined have been authorized by the temporal and spatial context that is informed by a complex historical interplay between forces of race, gender and class in the US South. To extrapolate the analysis applied to these findings to other selfies would be a misrepresentation of the arguments we have constructed here.

What we have attempted to do in this study is to use this very specific dataset as an entry point to thinking about these traditional feminine selfie practices, why women participate in them, and some of their consequences, particularly among white college women in the US South. In order to understand why women willingly engage in these practices, we draw on Weedon to argue that "we need a theory of the relationship between subjectivity and meaning, meaning and social value, the range of possible normal subject positions open to women, and the power and powerlessness invested in them" (Weedon 1987, 19). In other words, we seek to understand why it makes sense for women to engage in practices which may, to some, seem contrary to goals of gender equity and perhaps their own self-interest. In order to do so, we need to identify the subject positions available and understand what they offer women.

We approached this project with the knowledge that examining and critiquing women's practices has been and continues to be tricky business for feminist researchers. But avoiding research on the cultural practices of an entire group of people on the basis of not wanting to appear critical of our same gender group is not a tenable position for feminist researchers. Further, as Gavey points out, questioning women's activities:

does not require a didactic mode of engagement that judges and patronizes young women and berates them for not knowing what's (not) good for them. Feminism can raise questions, highlight contradictions, and invite new ways of seeing some of our shared-taken-for-granteds. Critique-particularly when focused on the cultural conditions of possibility rather than the individual-can be generous and respectful. Its effects can be enriching and ultimately affirming rather admonishing and hurtful. $(2012,722)$

In this study, we have sought to keep the focus on understanding the "cultural conditions of possibilities," particularly those shaped by postfeminism, southern traditional femininity and the demands of participating successfully on SNSs, to make sense of these selfie practices.

While recognizing that these forces, among others, shape the choices that young women make, there remains space to question and critique the foundations in which these practices are embedded. Further, in this neoliberal context, we want to specifically draw attention to the broader consequences of the "choices" individual women make by performing traditional femininity or posting selfies. Specifically, we want to draw attention to the reality that behaviors that might benefit women on an individual level can also have consequences for women as a group. This is also a tricky argument to engage, as it can appear to be denying agency or freedom to some groups of women, or creating a hierarchy of feminine performances. But how can we engage in dialogue about how rigid gender 
binaries are reproduced and maintained without identifying the ways in which some groups of women willingly contribute to their reinscription? McPherson voiced a similar concern in her discussion of the complexity of analyzing women's deployment of southern femininity:

while recognizing women's investments in specific modes of femininity, [feminists must] also retain a space to talk about the various ways such modes can still serve to bolster up the dominant order. One woman's pleasures, after all, can be tied to another's pain. To suggest that feminism must still at times operate a critique of specific forms of femininity (even while trying to understand their pull) is not to position feminism "wholly outside femininity" but rather to insist that being feminine is not all a southern woman should be. $(2003,193)$

If we are committed to destabilizing gender binaries and working toward a world in which bodies, and images of them, are not traded as capital, then there must be some attention paid to ways in which women's practices and behaviors can get in the way of these goals, while at the same time drawing attention to the structures that enable and inspire these processes in the first place. In addition, the present shift toward a normalization of misogyny, revealed through instances like support for U.S. presidential candidate Trump in spite of his repeated demeaning comments about women, or more recently, through the widely circulated report that now President Trump directed the women on his staff to "dress like women" (e.g. Fortin 2017), provides additional impetus for continued attention to the ways in which women's self-presentation is understood and framed across multiple media.

Theorizations of postfeminism offered by media studies scholars position the reemergence of the performance of traditional femininity, particularly within social media spaces, as a symptom and manifestation of neoliberalism. Through this lens, we read these selfies as both technologies constructing hyperfemininity and commodities within a visual economy in which traditional femininity has value. As a result of what is captured and circulated through Instagram, these selfies work as public pedagogy, schooling those who view the images on a particular version of gender norms and reinscribing a classed and raced version of femininity in the US South. It is important to note, however, that these pedagogies operate without a significant, oppositional response beyond those that characterize these practices as narcissistic or further marginalize the activities in which women engage. Because feminism has been positioned in popular culture as "achieved," the postfeminist and neoliberal discourses of individual agency that promote the curation of traditional femininities in online spaces circulate without parallel discourses that offer the tools to challenge either the impetus or consequences of these choices.

Disclosure statement - No potential conflict of interest was reported by the authors.

\section{References}

Brownmiller, Susan. 1984. Femininity. New York: Fawcett Columbine.

Butler, Judith. 1993. Bodies That Matter: On the Discursive Limits of "Sex". New York: Routledge. 
Dobson, A. S. 2014. "Performative Shamelessness on Young Women's Social Network Sites: Shielding the Self and Resisting Gender Melancholia." Feminism \& Psychology 24(1): 97-114. doi:10.1177/ 0959353513510651.

Duffy, B. E., and E. Hund. 2015. "'Having It All' on Social Media: Entrepreneurial Femininity and Self-Branding among Fashion Bloggers." Social Media + Society 1(2), doi:10.1177/2056305115604337.

Duggan, Maeve. 2015. “Mobile Messaging and Social Media 2015." Pew Research Center Internet Science Tech RSS. Accessed June 4, 2016. http://www.pewinternet.org/2015/08/19/mobilemessagingand-social-media-2015/.

Eler, Alicia. 2013. “The Feminist Politics of \#Selfies.” Hyperallergic RSS. Accessed May 15, 2014. http://hyperallergic.com/95150/the-radical-politics-of-selfies/.

Fortin, Jacey. 2017. “Dress Like a Woman? What Does That Mean." New York Times, February 3. https://www.nytimes.com/2017/02/03/style/trump-women-dress-code-white-house.html.

García-Favaro, Laura. 2015. "'Porn Trouble' on the Sexual Regime and Travels of Postfeminist Biologism." Australian Feminist Studies 30(86): 366-376.

Gavey, Nicola. 2012. “Beyond 'Empowerment'? Sexuality in a Sexist World.” Sex Roles 66(11-12): 718-724.

Gill, Rosalind. 2008. "Culture and Subjectivity in Neoliberal and Postfeminist Times." Subjectivity 25(1): 432-445. doi:10.1057/sub.2008.28.

Gill, Rosalind. 2016a. "Post-Postfeminism?: New Feminist Visibilities in Postfeminist Times." Feminist Media Studies 16 (4): 610-630. doi:10.1080/14680777.2016.1193293.

Gill, Rosalind. 2016b. "Postfeminism and the New Cultural Life of Feminism." Diffractions 6. https://lisbonconsortium.files.wordpress.com/2012/12/rosalind-gill_postfeminism-and-the-newcultural-life-of-feminism.pdf.

Gill, Rosalind, and Ngaire Donaghue. 2013. "As If Postfeminism Had Come True: The Turn to Agency in Cultural Studies of 'Sexualisation'." In Gender, Agency, and Coercion, edited by Sumi Madhok, Anne Phillips, and Kalpana Wilson, 240-258. New York: Palgrave MacMillon.

Gill, Rosalind, and Shani Orgad. 2015. “The Confidence Cult(ure)." Australian Feminist Studies 30(86): 324-344.

Giroux, Henry A. 2004. "Public Pedagogy and the Politics of Neo-Liberalism: Making the Political More Pedagogical." Policy Futures in Education 2: 494-503. doi:10.2304/pfie.2004.2.3.5.

Hamilton, L. 2007. “Trading On Heterosexuality: College Women's Gender Strategies and Homophobia." Gender E Society 21(2): 145-172. doi:10.1177/0891243206297604.

Hayward, Mark. 2013. "ATMs, Teleprompters, and Photobooths: A Short History of Neoliberal Optics." New Formations 80: 194-208.

Markham, Annette, and Elizabeth Buchanan. 2012. "Ethical Decision-Making and Internet Research." Association of Internet Researchers. https://aoir.org/reports/ethics2.pdf.

McPherson, Tara. 2003. Reconstructing Dixie: Race, Gender, and Nostalgia in the Imagined South. Durham: Duke University Press.

McRobbie, Angela. 2009. The Aftermath of Feminism: Gender, Culture and Social Change. London: Sage.

Mendelson, Andrew L., and Zizi Papacharissi. 2011. "Look at Us: Collective Narcissism in College Student Facebook Photo Galleries." In A Networked Self: Identity, Community and Culture on Social Network Sites, edited by Zizi Papacharissi, 251-273. New York: Routledge.

Moore, M., ed. 2013. University of Georgia Fact Book 2013. Athens, GA: University of Georgia Printing. Negra, Diane. 2009. What a Girl Wants? Fantasizing the Reclamation of Self in Postfeminism. London: Routledge. 
Pham, Minh-Ha T. 2015. "'I Click and Post and Breathe, Waiting for Others to See What I See': On \#FeministSelfies, Outfit Photos, and Networked Vanity." The Journal of Dress, Body E Culture 19(2): 221-242. doi:10.2752/175174115×14168357992436.

Ringrose, Jessica. 2013. Postfeminist Education? Girls and the Sexual Politics of Schooling. London: Routledge.

Ringrose, Jessica, and Laura Harvey. 2015. "Boobs, Back-off, Six Packs and Bits: Mediated Body Parts, Gendered Reward, and Sexual Shame in Teens' Sexting Images." Continuum 29(2): 205-217. doi:10 $.1080 / 10304312.2015 .1022952$.

Ringrose, Jessica, Laura Harvey, Rosalind Gill, and Sonia Livingstone. 2013. “Teen Girls, Sexual Double Standards and 'Sexting': Gendered Value in Digital Image Exchange." Feminist Theory 14(3): 305-323. doi:10.1177/1464700113499853.

Ryan, Erin Gloria. 2013. “Selfies Aren't Empowering. They're a Cry for Help.” Jezebel. Accessed June 1, 2014. http://jezebel.com/selfies-arent-empowering-theyre-a-cry-for-help-1468965365

Skeggs, Bev. 2001. “The Toilet Paper: Femininity, Class and Mis-Recognition.” Women's Studies International Forum 24: 295-307.

Skeggs, Bev. 2005. “The Making of Class and Gender through Visualizing Moral Subject Formation." Sociology 39(5): 965-982. doi:10.1177/0038038505058381.

Tasker, Yvonne, and Dianne Negra. 2007. “Introduction.” In Interrogating Postfeminism: Gender and the Politics of Popular Culture, edited by Yvonne Tasker and Diane Negra. Durham: Duke University Press.

Weedon, Chris. 1987. Feminist Practice and Poststructuralist Theory. Oxford, UK: B. Blackwell.

West, C., and D. H. Zimmerman. 1987. “Doing Gender.” Gender E Society 1(2): 125-151. doi:10.1177/ 0891243287001002002.

\section{Notes on contributors}

Dr. Mardi Schmeichel is an associate professor in the Department of Educational Theory and Practice and affiliate faculty in the Institute for Women's Studies at the University of Georgia. Her research interests include neoliberalism, social media, and sports culture.

Dr. Stacey L. Kerr is an assistant professor in the Department of Geography and Environmental Studies at Central Michigan University. She uses mobilities and feminist theories to explore issues in geography education, teacher education, and the spaces of educational technology and social media.

Dr. Chris Linder is an associate professor of College Student Affairs Administration at the University of Georgia. Prior to becoming faculty, Chris worked as a student affairs educator and administrator for 10 years, spending the majority of her career as a director of a campus-based women's center, supporting survivors of sexual violence. Chris's research interests include creating and maintaining equitable campus environments, specifically focusing on race and gender. 